\title{
Disease severity and symptoms among patients receiving monotherapy for COPD
}

\section{*Mark T Dransfielda, William Bailey ${ }^{a}$, Glenn Crater ${ }^{\mathrm{b}}$, Amanda Emmett ${ }^{\mathrm{b}}$, Dianne M O’Dell', Barbara Yawnc}

${ }^{a}$ UAB Lung Health Center, University of Alabama at Birmingham, Birmingham, AL, USA

${ }^{b}$ GlaxoSmithKline, Respiratory and Immuno-Inflammation Medicines Development Center, Research Triangle Park, NC, USA

Olmsted Medical Center, Rochester, MN, USA

Originally submitted 6th April 2010; resubmitted 4th June 2010; revised 30th June 2010; further revision 14th July, 2010; accepted 20th July 2010; online 30th September 2010

\begin{abstract}
Aim: To examine the burden of respiratory symptoms, quality of life and co-morbid illness in COPD patients receiving maintenance treatment in a real world setting.

Methods: In a single visit, patients with a physician's diagnosis of COPD who were receiving monotherapy with a long-acting bronchodilator (LABD) performed spirometry, completed symptom questionnaires, and reported their treatments, history of exacerbations and co-morbidities.

Results: We enrolled 1084 patients of whom 1072 had acceptable spirometry. 689 (64\%) had airflow obstruction (FEV $1 / F V C \leq 0.70)$ while $383(36 \%)$ failed to meet spirometric criteria for COPD despite receiving maintenance therapy and having comparable symptoms and comorbid illness. Among those with confirmed COPD, dyspnoea was worse in those with more severe airflow limitation though exacerbation frequency was comparable across COPD stages.

Conclusions: COPD is commonly diagnosed and treated in patients without airflow obstruction. Many COPD patients receiving LABD monotherapy continue to suffer significant symptoms, exacerbations and poor quality of life.

(C) 2011 Primary Care Respiratory Society UK. All rights reserved.

MT Dransfield et al. Prim Care Respir J 2011; 20(1): 46-53

doi:10.4104/pcrj.2010.00059
\end{abstract}

Keywords COPD, long-acting bronchodilator, spirometry, quality of life, disease severity, symptoms, monotherapy

\section{Introduction}

Despite declining smoking rates in the USA, chronic obstructive pulmonary disease (COPD) remains a major public health problem that affects more than one in 20 adults and a third of smokers..$^{1-3}$ The disease leads to more than 100,000 deaths each year and is associated with annual costs exceeding $\$ 40$ billion, more than twice that of asthma. ${ }^{1,4,5}$ Although often viewed as a disease cared for by pulmonologists, most COPD visits occur in primary care practices. ${ }^{6}$ Our understanding of the natural history of COPD is skewed to the more severe stages of COPD, those patients who are most often required for clinical trial inclusion. Few studies have focused on mild to moderate COPD or enrolled patients with the multiple co-morbidities that occur in this population. ' Depression, cardiovascular disease and osteoporosis have been documented in as many as $40 \%$ of patients with severe and very severe COPD, but little is known about the prevalence of these morbidities in those with more moderate disease. ${ }^{8,9}$

Consequently, we have limited information on COPD patients seen at the less disabling stages that account for much of the care provided by family physicians and general internists. We also know little about how these "real world" patients are being recognised, how frequently spirometry is used, and the degree of lung function impairment in those diagnosed with COPD. In addition, there is little published data about how treatment for these patients is adherent to COPD management guidelines and whether or not they remain symptomatic despite therapy.

\footnotetext{
* Corresponding author: Dr Mark Dransfield, Division of Pulmonary, Allergy and Critical Care Medicine, University of Alabama at Birmingham, 422 THT, 1900 University Blvd., Birmingham, Alabama, 35294, USA. Tel: +1 2059345425 Fax: +1 2059346229 E-mail: mdransfield99@msn.com
} 
This study was designed therefore to provide specific information about COPD patients seen in real world practices. Knowing the symptom burden, lung function, types of care provided and response to that care, can help tailor future educational endeavours by primary care physicians based not on assumptions or even self-reported needs ${ }^{10}$ but rather care based on the actual needs and symptoms of patients. In addition, we hoped to provide new information to help close some of the many gaps that continue to exist in our understanding of the impact of COPD across the full spectrum of disease severity.

\section{Methods}

\section{Patients}

Patients were male and female aged $\geq 40$ years and were current or previous smokers with a smoking history of $\geq 10$ pack-years. Patients had an established history of COPD as diagnosed by a physician. Medical records were not obtained to confirm a verbal report of a COPD diagnosis. Investigators classified patients as having predominantly emphysema, predominantly chronic bronchitis or features of both based on their overall clinical impression. Patients must have been regularly taking only one long-acting bronchodilator (LABD) for $\geq 1$ month prior to the study visit.

Patients were excluded if they had had previous lung surgery, respiratory disorders other than COPD (including asthma), or a COPD exacerbation (defined as worsening cough, sputum, or dyspnoea that required treatment with systemic corticosteroids, antibiotics, or an emergency department visit and/or hospitalisation) in the six weeks prior to the study visit. Patients were also excluded if they had been taking any of the following respiratory medications in the three months prior to the study visit: ipratropium/albuterol (salbutamol) combinations used >three times per day; inhaled corticosteroids (ICS); ICS/longacting beta-agonist combination inhalers; theophylline preparations; or oral $\beta_{2}$-agonists.

\section{Study design}

This study was conducted at 56 primary care and specialty centers in the USA. An ethics committee approved the study at each site and all patients provided written informed consent prior to the conduct of any study procedures. Eligible patients completed a single study visit encompassing all required assessments. Patients did not receive blinded study medication.

\section{Measurements}

Pre- and post-bronchodilator spirometry was performed. For post-bronchodilator spirometry, patients self-administered four puffs (360 mcg) of albuterol (salbutamol) via a metereddose inhaler (MDI) with a spacer. Spirometry was performed using standardised spirometry equipment provided by nSpire Health Inc, Longmont, CO. Patients with obstruction were staged according to Global initiative for Obstructive Lung Disease (GOLD) criteria. ${ }^{11}$

Dyspnoea was measured by the modified Medical Research Council (mMRC) dyspnoea scale. ${ }^{12}$ This scale contains five items that rate the degree of breathlessness from a score of 0 (no dyspnoea) to 4 (very severe dyspnoea).

Patients were given a quality of life questionnaire, the Chronic Respiratory Disease Questionnaire Self AdministeredStandardised (CRQ-SAS) ${ }^{13}$ to complete. The CRQ-SAS includes 20 items across four domains: dyspnoea, fatigue, emotional function, and mastery. Patients rated their experience on a 7point scale ranging from 1 (maximum impairment) to 7 (no impairment). The Minimal Clinically Important Difference (MCID) for each domain is 0.5. Use of the CRQ-SAS, authored by Drs. Gordon Guyatt and Holger Schunemann, was made under licence from McMaster University, Hamilton, Canada.

The number of COPD exacerbations experienced within the past 12 months, the average number of puffs from all short-acting bronchodilator MDIs and/or number of nebules used in the two weeks prior to the study visit, and diagnosis and/or treatment for specific medical conditions related to cardiovascular, psychiatric (anxiety or depression) and/or bone disorders, were obtained by self-report.

\section{Statistical analysis}

Though the study was cross-sectional in design, a sample size calculation was performed based on estimated spirometry results. It was estimated that approximately $80 \%$ of patients would have a post-albuterol (salbutamol) forced expiratory volume in one second $\left(\mathrm{FEV}_{1}\right)<80 \%$ predicted. A sample size of 1000 patients would provide a $95 \%$ confidence interval of this proportion of patients (80\%) with precision of 2.5 percentage points. The recruited sample size of 1072 with spirometry data provided a $95 \%$ confidence interval of the actual proportion of patients $(70 \%)$ with a post-albuterol (salbutamol) $\mathrm{FEV}_{1}<80 \%$ predicted normal with a precision of 2.7 percentage points.

Descriptive summaries of assessments were generated overall and by subgroup. Subgroups were defined from the analysis population as patients with a post-albuterol (salbutamol) $\mathrm{FEV}_{1} / \mathrm{FVC}$ ratio $\leq 0.70$ versus $>0.70$. For patients with an $\mathrm{FEV}_{1} / \mathrm{FVC} \leq 0.70$, subgroups based on postalbuterol (salbutamol) FEV1 \% predicted values ( $<80 \%$ versus $\geq 80 \%$ and $<50 \%$ versus $\geq 50 \%$ ) were also defined. COPD exacerbations, short-acting bronchodilator use, mMRC dyspnoea and CRQ-SAS domain scores were compared between subgroups. Differences in continuous measures between subgroups of patients were presented as least squares means from analysis of variance models adjusting for investigator. Associations between subgroups of patients for categorical measures were presented by calculating odds ratios using Cochran-Mantel-Haenszel tests stratified by 
MT Dransfield et al.

investigator. Statistical analyses were performed using SAS Version 9.1.

\section{Results}

\section{Patients and lung function}

We enrolled 1084 patients at 56 centers (median 17 patients per site). The most common LABD used was tiotropium (76\%), followed by formoterol (14\%) and salmeterol (9\%). The mean length of LABD therapy for all patients was approximately $1-2$ years. For the $\mathrm{FEV}_{1} / \mathrm{FVC} \leq 0.70$ and $>0.70$ groups, the most commonly used LABD was tiotropium (77\% and $75 \%$, respectively), formoterol $(15 \%$ and $11 \%$, respectively), and salmeterol ( $8 \%$ and $12 \%$, respectively).

Of the 1084 patients enrolled, 1072 patients had an acceptable spirometry measurement that could be used for analysis. 689 (64\%) had a post-albuterol (salbutamol) $\mathrm{FEV}_{1} / \mathrm{FVC}$ ratio of $\leq 0.70$ confirming the presence of airflow obstruction compatible with COPD, while 383 (36\% patients) had a post-albuterol (salbutamol) $\mathrm{FEV}_{1} / \mathrm{FVC}$ ratio of $>0.70$. Among those with airflow obstruction, $89 \%$ had COPD at GOLD stage II or higher, though there were patients across the spectrum of disease severity. Table 1 provides the mean post-bronchodilator $\mathrm{FEV}_{1}$ for patients in each of these groups. The mean bronchodilator response among those with airflow limitation was $8.9 \%(112 \mathrm{~mL})$ while in those with normal $\mathrm{FEV}_{1} / \mathrm{FVC}$ ratios bronchodilator reversibility was $4.3 \%(90 \mathrm{~mL})$. $\mathrm{FEV}_{1} / \mathrm{FVC} \leq 0.70$ vs. $>0.70$ analysis

Demographic characteristics for the FEV $1 / F V C \leq 0.70,>0.70$, and total population are provided in Table 2 . The $\leq 0.70$ group were older $(p<0.001)$, included more males $(p=0.003)$, had more emphysema and less chronic bronchitis $(p=0.014)$, and reported more pack-years of smoking $(p<0.001)$ compared to the $>0.70$ group.

\begin{tabular}{|c|c|c|}
\hline \multicolumn{3}{|c|}{$\mathrm{FEV}_{1} / \mathrm{FVC}>0.70$} \\
\hline $\begin{array}{l}\text { Post-BD FEV } 1 \% \\
\text { predicted category }\end{array}$ & $n, \%$ & $\begin{array}{c}\text { Mean Post-BD } \\
\text { FEV }_{1} \% \text { predicted }\end{array}$ \\
\hline All & $383(100)$ & 84.8 \\
\hline$<80 \%$ & $144(38)$ & 68.1 \\
\hline$>80 \%$ & $239(62)$ & 94.9 \\
\hline \multicolumn{3}{|c|}{$\mathrm{FEV}_{1} / \mathrm{FVC} \leq 0.70$} \\
\hline $\begin{array}{l}\text { GOLD Stage (Post-BD } \\
\text { FEV }_{1} \% \text { predicted) }\end{array}$ & $n, \%$ & $\begin{array}{c}\text { Mean Post-BD } \\
\mathrm{FEV}_{1} \% \text { predicted }\end{array}$ \\
\hline $\mathrm{I}(\geq 80 \%)$ & $79(11)$ & 89.2 \\
\hline II $(\geq 50-<80 \%)$ & $375(54)$ & 63.7 \\
\hline III ( $>30-<50 \%)$ & $186(27)$ & 41.1 \\
\hline IV $(<30 \%)$ & $49(7)$ & 25.6 \\
\hline
\end{tabular}

Few statistically significant differences in major outcomes were observed between these two groups. Reports of COPD exacerbations in the past 12 months and co-morbid disorders were similar. There were no statistically significant differences in albuterol (salbutamol) use. Table 3 provides the mMRC scores and CRQ-SAS domain scores between these two groups. The $>0.70$ group had statistically lower scores on the emotional function and fatigue domains than the $\leq 0.70$ group.

\section{$\mathrm{FEV}_{1} / \mathrm{FVC} \leq 0.70$ group analysis mMRC dyspnoea scores}

Across all FEV 1 severities, the majority of patients reported slight to moderate dyspnoea (Figure 1). There was a statistically significant difference in the mean mMRC score between the $<80 \%$ and $\geq 80 \%$ groups ( 1.7 vs. $1.5 ; p=0.019$ ) and between the $<50 \%$ and $\geq 50 \%$ groups (1.9 vs. 1.6 ; $\mathrm{p}=0.004)$. Both of these differences were less than the MCID.

\section{COPD exacerbations}

The majority of patients reported no exacerbations requiring hospitalisation or oral corticosteroids/antibiotics in the 12 months prion to the study visit. There were no statistically significant differences in the reporting of either type of exacerbation between the $<80 \%$ and $\geq 80 \%$ groups or the $<50 \%$ and $\geq 50 \%$ groups (Table 4 ).

\section{Albuterol (salbutamol) use}

Mean albuterol (salbutamol) use (puffs/day) was nonstatistically greater among the groups with more severe airflow limitation ( 4.0 vs. 3.9 between the $<80 \%$ and $\geq 80 \%$ groups; 5.2 vs. 3.3 between the $<50 \%$ and $\geq 50 \%$ groups).

\section{Cardiovascular, psychiatric, and bone disorders}

The report of any or specific past cardiovascular, psychiatric, and bone disorders was common across all subgroups. Table 5 presents the reporting of a current diagnosis of these disorders. Though there was a trend to more frequent

\section{Table 2. Demographic and disease characteristics}

\begin{tabular}{lcccc} 
& $\begin{array}{c}\text { Total } \\
\mathrm{n}=1084\end{array}$ & $\begin{array}{c}\leq 0.70 \\
\mathrm{n}=689\end{array}$ & $\begin{array}{c}>0.70 \\
\mathrm{n}=383\end{array}$ & $\mathrm{p}$-value \\
\hline Age (mean yrs) & 61.2 & 63.7 & 56.7 & $<0.001$ \\
\hline Sex, \% Male & 50 & 53 & 46 & 0.003 \\
\hline Race, \% White/AA & $86 / 13$ & $90 / 10$ & $79 / 20$ & 0.083 \\
\hline $\begin{array}{l}\text { Duration COPD } \\
\text { (mean yrs) }\end{array}$ & 6.4 & 6.6 & 6.0 & 0.117 \\
\hline $\begin{array}{l}\text { COPD type } \\
\text { \% emphysema/ }\end{array}$ & & & & \\
\% chronic bronchitis) & $43 / 44$ & $47 / 38$ & $34 / 55$ & 0.014 \\
\hline Current Smoker, \% & 59 & 54 & 70 & 0.056 \\
\hline Pack-years (mean) & 47.8 & 51.8 & 40.7 & $<0.001$ \\
\hline Mean BMl, kg/m² & 29.0 & 28.3 & 30.4 & $<0.001$
\end{tabular}




\begin{tabular}{|c|c|c|}
\hline & $\begin{array}{c}\mathrm{FEV}_{1} / \\
\text { FVC } \leq 0.70 \\
\mathrm{~N}=689\end{array}$ & $\begin{array}{c}\mathrm{FEV}_{1} / \\
\mathrm{FVC}>0.70 \\
\mathrm{~N}=383\end{array}$ \\
\hline \multicolumn{3}{|l|}{ Dyspnoea } \\
\hline Mean (SE) & $4.6(0.05)$ & $4.5(0.08)$ \\
\hline Least Squares Mean Difference (SE) & \multicolumn{2}{|c|}{$0.1(0.10)$} \\
\hline $95 \% \mathrm{Cl}$ & \multicolumn{2}{|c|}{$-0.1,0.3$} \\
\hline$p$-value & \multicolumn{2}{|c|}{0.519} \\
\hline \multicolumn{3}{|l|}{ Fatigue } \\
\hline Mean (SE) & $3.9(0.05)$ & $3.6(0.07)$ \\
\hline Least Squares Mean Difference (SE) & \multicolumn{2}{|c|}{$0.4(0.09)$} \\
\hline $95 \% \mathrm{Cl}$ & \multicolumn{2}{|c|}{$0.2,0.5$} \\
\hline$p$-value & \multicolumn{2}{|c|}{$<0.001$} \\
\hline \multicolumn{3}{|l|}{ Emotional Function } \\
\hline Mean (SE) & $4.5(0.05)$ & $4.0(0.07)$ \\
\hline Least Squares Mean Difference (SE) & \multicolumn{2}{|c|}{$0.4(0.09)$} \\
\hline $95 \% \mathrm{Cl}$ & \multicolumn{2}{|c|}{$0.2,0.6$} \\
\hline p-value & \multicolumn{2}{|c|}{$<0.001$} \\
\hline \multicolumn{3}{|l|}{ Mastery } \\
\hline Mean (SE) & $4.8(0.06)$ & $4.4(0.07)$ \\
\hline Least Squares Mean Difference (SE) & \multicolumn{2}{|c|}{$0.2(0.09)$} \\
\hline $95 \% \mathrm{Cl}$ & \multicolumn{2}{|c|}{$-0.0,0.4$} \\
\hline$p$-value & \multicolumn{2}{|c|}{0.060} \\
\hline \multicolumn{3}{|l|}{ mMRC Dyspnoea Scores } \\
\hline Mean (SE) & $1.7(0.04)$ & $1.7(0.05)$ \\
\hline Least Squares Mean Difference (SE) & $0.1(0.07)$ & \\
\hline $95 \% \mathrm{Cl}$ & $-0.0,0.2$ & \\
\hline$p$-value & 0.069 & \\
\hline
\end{tabular}

reporting of cardiovascular disorders in those with greater airflow limitation, this was not statistically significant after adjustment for investigator variability.

\section{CRQ-SAS domain scores}

Table 6 presents the mean domain scores for each spirometric group. The groups with greater airflow limitation had statistically significantly more impairment on the dyspnoea domain, and these differences met the MCID. Similar results were observed for the mastery domain with the $<50 \%$ group having more impairment compared to the $\geq 50 \%$ group (4. 6 vs. 4.9 , respectively, $p=0.005)$ though this was less than the MCID.

\section{Safety}

Five patients experienced an adverse event (AE) which included tooth fracture, hypoglycemia, tremor, petechiae, and hypertension. The petechial rash was considered related to investigational procedure, and the event resolved.
Figure 1. mMRC dyspnoea scores in the FEV $1 / F V C \leq 0.70$ group by post-bronchodilator $\mathrm{FEV}_{1}$ percent predicted.

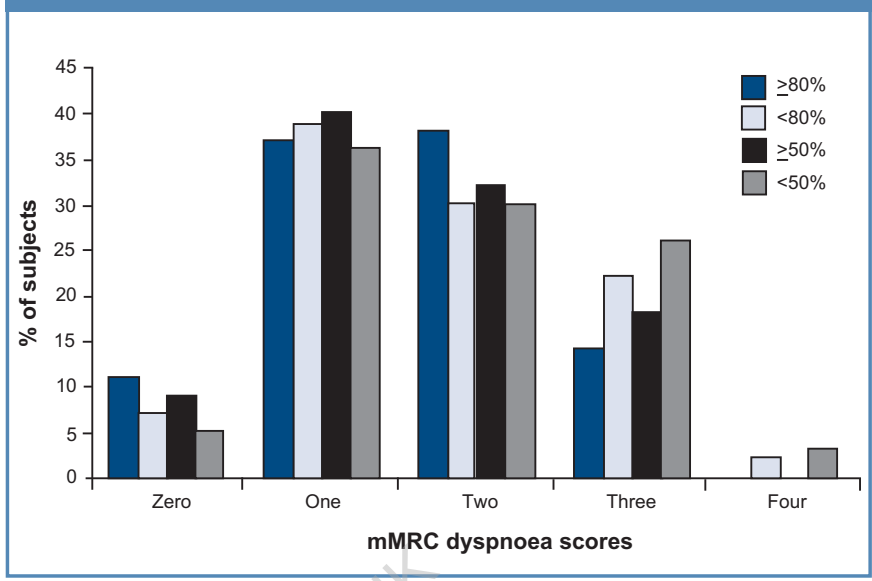

Table 4. COPD exacerbations in the $F_{1} V_{1} / F V C \leq 0.70$

group by post-bronchodilator $\mathrm{FEV}_{1}$ percent predicted.

\begin{tabular}{|c|c|c|c|c|}
\hline 6 & $\begin{array}{l}<80 \% \\
n=610\end{array}$ & $\begin{array}{c}\geq 80 \% \\
n=79\end{array}$ & $\begin{array}{l}<50 \% \\
n=235\end{array}$ & $\begin{array}{l}\geq 50 \% \\
n=454\end{array}$ \\
\hline \multicolumn{5}{|c|}{ Hospitalisation, n \% } \\
\hline Yes $\quad 0$ & $33(5)$ & $6(8)$ & $16(7)$ & $23(5)$ \\
\hline Odds Ratio & \multicolumn{2}{|c|}{0.44} & \multicolumn{2}{|c|}{1.13} \\
\hline $95 \% \mathrm{Cl}$ & \multicolumn{2}{|c|}{$0.16,1.22$} & \multicolumn{2}{|c|}{$0.54,2.36$} \\
\hline$p$-value & \multicolumn{2}{|c|}{0.105} & \multicolumn{2}{|c|}{0.748} \\
\hline \multicolumn{5}{|c|}{ OCS/Antibiotic, n \% } \\
\hline Yes & $186(30)$ & $33(42)$ & $73(31)$ & $146(32)$ \\
\hline Odds Ratio & \multicolumn{2}{|c|}{1.09} & \multicolumn{2}{|c|}{1.35} \\
\hline $95 \% \mathrm{Cl}$ & \multicolumn{2}{|c|}{$0.55,2.18$} & \multicolumn{2}{|c|}{$0.89,2.06$} \\
\hline$p$-value & \multicolumn{2}{|c|}{0.803} & \multicolumn{2}{|c|}{0.156} \\
\hline
\end{tabular}

Odds ratios were calculated as the more severe group divided by the less severe group.

\section{Discussion}

The primary objective of our study was to examine the burden of COPD and its associated co-morbidities in a real-world clinical setting. Specifically, we aimed to examine these impacts in COPD patients who had been judged sufficiently symptomatic to warrant the prescription of maintenance therapy with a single LABD.

The current GOLD guidelines rate the severity of COPD and recommend the titration of inhaled medications based primarily on the degree of impairment in $\mathrm{FEV}_{1} .{ }^{11}$ It has been shown previously that $\mathrm{FEV}_{1}$ correlates poorly with dyspnoea, and that measures of hyperinflation (such as reduced inspiratory capacity) may correlate better with difficulties in performing routine physical activity even among patients with mild disease. ${ }^{14,15}$ Though we did find that patients with more severe airflow obstruction reported statistically greater dyspnoea (mMRC 1.9 among those with $\mathrm{FEV}_{1}<50 \%$ vs. 1.6 among those with $\mathrm{FEV}_{1}$ 
Table 5. Current cardiovascular, psychiatric, and bone disorders reported in $\geq 5 \%$ of patients in the $\mathrm{FEV}_{1} / \mathrm{FVC}$ $\leq 0.70$ group by post-bronchodilator $F V_{1}$

\begin{tabular}{|c|c|c|c|c|}
\hline & $\begin{array}{l}<80 \% \\
n=610\end{array}$ & $\begin{array}{c}\geq 80 \% \\
\mathrm{n}=79\end{array}$ & $\begin{array}{l}<50 \% \\
n=235\end{array}$ & $\begin{array}{l}\geq 50 \% \\
\mathrm{n}=454\end{array}$ \\
\hline $\begin{array}{l}\text { Any Cardiovascular, } \\
\text { Psychiatric, or Bone }\end{array}$ & & & & \\
\hline Condition, n \%, & $451(74)$ & $47(59)$ & $171(73)$ & $327(72)$ \\
\hline \multicolumn{5}{|c|}{ Cardiovascular Disorders, n \% } \\
\hline Any Condition & $368(60)$ & $38(48)$ & $145(62)$ & $261(57)$ \\
\hline Hypertension & $310(51)$ & $29(37)$ & $118(50)$ & $221(49)$ \\
\hline Coronary Artery Disease & $69(11)$ & $6(8)$ & $25(11)$ & $50(11)$ \\
\hline Atherosclerosis & $40(7)$ & $4(5)$ & $20(9)$ & $24(5)$ \\
\hline Arrhythmia & $35(6)$ & $8(10)$ & $15(6)$ & $28(6)$ \\
\hline Heart Failure & $19(3)$ & $5(6)$ & $10(4)$ & $14(3)$ \\
\hline Peripheral Vascular Disease & $19(3)$ & $4(5)$ & $5(2)$ & $18(4)$ \\
\hline \multicolumn{5}{|l|}{ Psychiatric Disorders, n \% } \\
\hline Any Condition & $155(25)$ & $14(18)$ & $58(25)$ & $111(24)$ \\
\hline Generalized Anxiety Disorde & r $86(14)$ & $8(10)$ & 35 (15) & $59(13)$ \\
\hline Major Depressive Disorder & $74(12)$ & $10(13)$ & $27(11)$ & $57(13)$ \\
\hline \multicolumn{5}{|l|}{ Recurrent Episode } \\
\hline Social Anxiety Disorder & $16(3)$ & $3(4)$ & $6(3)$ & $13(3)$ \\
\hline \multicolumn{5}{|l|}{ Bone Diseases, n \% } \\
\hline Any Condition & $82(13)$ & $10(13)$ & $32(14)$ & $60(13)$ \\
\hline Osteoporosis & $67(11)$ & $10(13)$ & $27(11)$ & $50(11)$ \\
\hline Osteopenia & $27(4)$ & $2(3)$ & $11(5)$ & $18(4)$ \\
\hline
\end{tabular}

$\geq 50 \%, p=0.004$ ), this did not approach the threshold thought to be clinically significant. ${ }^{16}$ Patients with $\mathrm{FEV}_{1}<50 \%$ did require more frequent use of albuterol (salbutamol) (5.2 vs. 3.3 puffs/day) although this was not statistically significant.

Several previous studies have suggested that COPD exacerbations become more common and more serious as baseline lung function worsens. ${ }^{17-19}$ A recent prospective observational study of COPD patients in the primary care setting $(n=201)$ has suggested that acute exacerbations affect patients across the spectrum of disease severity; O'Reilly et al. found an overall exacerbation rate of $77 \%$ and that the rate of exacerbation was comparable in those with an $\mathrm{FEV}_{1}$ greater or less than $50 \%$ predicted whether based on symptom diaries or healthcare utilisation. ${ }^{20}$ Similarly, we found no relationship between $\mathrm{FEV}_{1}$ and the frequency of mild to moderate acute exacerbations requiring oral corticosteroids and/or antibiotics (overall rate $32 \%$ ) or severe exacerbations requiring hospitalisation (overall rate $6 \%$ ). These data, as well as studies suggesting that up to $50 \%$ of exacerbations go unreported despite adversely affecting quality of life, suggest that acute exacerbations are a complication of COPD per se, irrespective of severity. ${ }^{18,21}$
Table 6. CRQ-SAS domain scores in the $\mathrm{FEV}_{1} / \mathrm{FVC} \leq \mathbf{0 . 7 0}$ group by post-bronchodilator $\mathrm{FEV}_{1}$ percent predicted.

\begin{tabular}{|c|c|c|c|c|}
\hline & $\begin{array}{l}<80 \% \\
n=610\end{array}$ & $\begin{array}{c}\geq 80 \% \\
\mathrm{n}=79\end{array}$ & $\begin{array}{l}<50 \% \\
n=235\end{array}$ & $\begin{array}{l}\geq 50 \% \\
n=454\end{array}$ \\
\hline \multicolumn{5}{|l|}{ Dyspnoea } \\
\hline Mean (SE) & $4.5(0.06)$ & $5.0(0.13)$ & $4.2(0.09)$ & $4.8(0.06)$ \\
\hline $\begin{array}{l}\text { Least Squares Mean } \\
\text { Difference (SE) }\end{array}$ & \multicolumn{2}{|c|}{$-0.5(0.17)$} & \multicolumn{2}{|c|}{$-0.5(0.11)$} \\
\hline $95 \% \mathrm{Cl}$ & \multicolumn{2}{|c|}{$-0.8,-0.1$} & \multicolumn{2}{|c|}{$-0.8,-0.3$} \\
\hline$p$-value & \multicolumn{2}{|c|}{0.006} & \multicolumn{2}{|c|}{$<0.001$} \\
\hline \multicolumn{5}{|l|}{ Fatigue } \\
\hline Mean (SE) & $3.9(0.05)$ & $3.9(0.14)$ & $3.8(0.09)$ & $3.9(0.06)$ \\
\hline $\begin{array}{l}\text { Least Squares Mean } \\
\text { Difference (SE) }\end{array}$ & \multicolumn{2}{|c|}{$-0.0(0.16)$} & \multicolumn{2}{|c|}{$-0.2(0.11)$} \\
\hline $95 \% \mathrm{Cl}$ & \multicolumn{2}{|c|}{$-0.3,0.3$} & \multicolumn{2}{|c|}{$-0.4,0.0$} \\
\hline $\mathrm{p}$-value & \multicolumn{2}{|c|}{0.846} & \multicolumn{2}{|c|}{0.052} \\
\hline \multicolumn{5}{|l|}{ Emotional Function } \\
\hline Mean (SE) & $4.6(0.05)$ & $4.4(0.15)$ & $4.6(0.09)$ & $4.5(0.06)$ \\
\hline $\begin{array}{l}\text { Least Squares Mean } \\
\text { Difference (SE) }\end{array}$ & \multicolumn{2}{|c|}{$0.1(0.15)$} & \multicolumn{2}{|c|}{$-0.1(0.10)$} \\
\hline $95 \% \mathrm{Cl}$ & \multicolumn{2}{|c|}{$-0.2,0.4$} & \multicolumn{2}{|c|}{$-0.3,0.1$} \\
\hline p-value & \multicolumn{2}{|c|}{0.701} & \multicolumn{2}{|c|}{0.515} \\
\hline \multicolumn{5}{|l|}{ Mastery } \\
\hline Mean (SE) & $4.8(0.06)$ & $4.9(0.14)$ & $4.6(0.09)$ & $4.9(0.07)$ \\
\hline $\begin{array}{l}\text { Least Squares Mean } \\
\text { Difference (SE) }\end{array}$ & \multicolumn{2}{|c|}{$-0.2(0.17)$} & \multicolumn{2}{|c|}{$-0.3(0.11)$} \\
\hline $95 \% \mathrm{Cl}$ & \multicolumn{2}{|c|}{$-0.6,0.1$} & \multicolumn{2}{|c|}{$-0.5,-0.1$} \\
\hline$p$-value & \multicolumn{2}{|c|}{0.153} & \multicolumn{2}{|c|}{0.005} \\
\hline
\end{tabular}

We did observe some differences in quality of life based on lung function impairment in those with airflow obstruction (FEV $1 / F V C \leq 0.70)$. Patients with an $\mathrm{FEV}_{1}<50 \%$ had worse scores on the dyspnoea domain than those with $\mathrm{FEV}_{1} \geq 50 \%$ that were both statistically and clinically significant. ${ }^{16}$ This contrasts with the minimal difference in mMRC scores between these two groups, perhaps in part reflecting the poor sensitivity of the mMRC to differentiate patients' clinical status. We also observed similarly worse mastery scores among patients with greater lung function impairment though this difference was not clinically significant. We found no association between the severity of airflow limitation and scores on the fatigue and emotional function domains of the CRQ-SAS. Overall, these findings support the conclusion that $\mathrm{FEV}_{1}$ cannot be used alone to predict overall quality of life for an individual patient with COPD.

Though spirometry is essential to establish the presence of airflow limitation and to diagnose COPD, it is not adequate to fully assess the impact and severity of the disease. Additional tests that can be useful in differentiating the diagnosis and characterising the manifestations of COPD include chest 
radiography, measurement of lung volumes and diffusing capacity of carbon monoxide (DLCO), and resting and exercise oxygen saturation levels. ${ }^{22}$ In addition to the mMRC dyspnoea assessment which is simple and predictive of prognosis particularly when incorporated into the multidimensional BODE inde $\mathrm{x}^{23}$ - recent studies have validated an 8-item questionnaire, the COPD Assessment Test (CAT), as a measure of quality of life. ${ }^{24}$ It is also becoming clear that $\mathrm{CT}$ scans can provide quantitative measures of both emphysema and airways disease and that each correlates with specific phenotypic characteristics. ${ }^{25}$ Recent guidelines, including those published by the National Institute for Clinical Excellence in the UK, and the American, Canadian and European Thoracic Societies, have increasingly recognised the need to incorporate non-spirometric measures in assessing COPD and determining appropriate therapy. ${ }^{22,26,27}$ These guidelines support the prescription of additional therapies for patients with ongoing respiratory symptoms and poor quality of life independent of lung function impairment.

It is increasingly apparent that COPD patients suffer from a multitude of co-morbid illnesses. " Buffels et al. have shown that the average COPD patient suffers from more than three concurrent illnesses which complicate their care. ${ }^{28}$ In our study, cardiovascular diagnoses were very common in the COPD population as a whole $(>50 \%)$ and more frequent in those with lower $\mathrm{FEV}_{1}$. This is consistent with prior epidemiological data suggesting that independent of other factors, the risk for cardiovascular disease increases by $10 \%$ for every $10 \%$ fall in FEV $1 .{ }^{29}$ As in previous studies, ${ }^{8,9}$ we found that depression was common in our COPD population though it was not more frequent in those with more severe airflow limitation. Though less well examined in the current literature, we also observed that anxiety disorders were frequently reported across the spectrum of COPD severity. This is important since anxiety has been shown to correlate independently with poor COPD-related outcomes including reduced overall quality of life, reduced exercise tolerance, and more frequent exacerbations. ${ }^{30}$

An unexpected finding was that $36 \%$ of enrollees did not have airflow limitation and therefore did not meet conventional criteria for COPD despite a physician's diagnosis and ongoing treatment with a LABD. Despite this, we found no differences in dyspnoea scores, the rate of COPD-related exacerbations, or the frequency of co-morbid illness in patients with $\mathrm{FEV}_{1} / \mathrm{FVC}>0.70$ compared to those with ratios $\leq 0.70$. We did observe a trend towards lower use of rescue albuterol (salbutamol) among patients in the $>0.70$ group suggesting that the medications were not beneficial. The explanations for these observations are not clear. Though restrictive physiology can be the result of obesity which can also be associated with dyspnoea, we found the mean BMI between the $>0.70$ and $\leq 0.70$ groups to be similar. We also found that patients with a normal $F E V_{1} / F V C$ ratio had greater impairment in the emotional function and fatigue domains of the
CRQ-SAS and were more often active smokers. These factors may be associated with impaired coping mechanisms that in turn led to healthcare utilisation and a physician diagnosis of COPD. Additionally, the $>0.70$ group were more frequently classified as having chronic bronchitis and the presence of this symptomatic phenotype may have incorrectly led to the diagnosis of COPD when in fact these patients were asthmatic. It should be noted that long-acting bronchodilators would not be prescribed by many practitioners for patients without COPD-induced airflow obstruction as they are likely to be at best ineffective (e.g. for pulmonary fibrosis or congestive heart failure) or at worst inappropriate (e.g. asthma). ${ }^{31}$ We should highlight that although both COPD and asthma are associated with airflow limitation it is important for clinicians to attempt to differentiate the two as their pathogenesis, prognosis and response to therapy differ. The NICE guidelines offer one diagnostic approach based on clinical characteristics including age of onset of respiratory complaints, presence of productive cough and variability in symptoms over time. ${ }^{26}$ Importantly, given the major benefits of ICS in asthma, guidelines recommend that patients be treated with these agents when clinicians are uncertain which illness is present. ${ }^{22}$

The study has several limitations. First we relied on patient reporting of COPD diagnosis, prior exacerbations, co-morbid illness, and medication use. Though recall bias may impact on these data, it is unlikely that there would be systematic error across the population. Second, though we aimed to exclude patients with a diagnosis of asthma we did not have access to patients' prior medical records to determine if they had been previously diagnosed with the disease or undergone spirometry. However, although bronchodilator reversibility cannot be used to differentiate COPD from asthma definitively, the level of response we observed in both the obstructed and non-obstructed groups was quite low and comparable to previous clinical trials in COPD. ${ }^{32-34}$ It remains possible that some patients in both groups were asthmatics who had been misclassified as having COPD. The absence of medical records also prevented us from evaluating the providers' differential diagnoses and it is possible that patients with other respiratory diseases such as interstitial fibrosis could have been included. It is notable, however, that only 144 of the 1072 participants had an $\mathrm{FEV}_{1} / \mathrm{FVC}>0.70$ and $\mathrm{FEV}_{1}$ (\% predicted) $\leq 80 \%$ compatible with physiologic restriction. Lastly, in contrast to many clinical trials that recruit patients on the basis of qualifying lung function results, we recruited patients who had previously been diagnosed with COPD and prescribed maintenance therapy. As this would bias our sample to a group of symptomatic participants, it may have reduced the likelihood of observing a relationship between degree of airflow limitation and the severity of these symptoms.

We conclude that physicians commonly diagnose and treat COPD in current and former smokers who do not have airflow obstruction. Though many of these patients report significant 
Our study was designed to examine the impact of COPD in a real world setting. We unexpectedly found that many patients did not meet spirometric criteria for COPD despite a physician diagnosis. We also found that their burden of respiratory complaints was comparable to that observed in patients with confirmed airflow obstruction. Inclusion of only the latter would have hidden these findings that raise questions about physician behavior and factors influencing healthcare utilisation. Several clinical lessons can be learned from the study: 1) Respiratory symptoms should not be attributed to COPD without confirmation of obstruction; 2) While important in COPD diagnosis, spirometry does not adequately assess the impact of the disease and; 3) Many patients receiving $L A B D$ monotherapy continue to experience significant symptoms.

dyspnoea and poor quality of life, these symptoms cannot be attributed to COPD and providers should consider alternative diagnoses including depression and cardiovascular disease which occur frequently in this group. In addition, though COPD patients with more severe airflow limitation suffer more respiratory symptoms, worse quality of life and greater co-morbidity than those with more mild impairment, these differences are modest and lung function alone does not adequately assess the impact of the disease. Finally, many patients receiving $L A B D$ monotherapy continue to experience significant symptoms and more aggressive therapy may be indicated.

\section{Acknowledgements and authorship declaration}

$M D, W B, G C, A E, D O$ and $B Y$ were involved with the initial concept of the paper, were extensively involved with the writing, and retained full editorial control throughout the development of the manuscript. Final approval was solely endorsed by the authors. All authors meet the criteria for authorship set forth by the International Committee for Medical Journal Editors. The authors wish to acknowledge Andrea Morris, employed by GSK, for editorial assistance and critical review during the development of this manuscript.

\section{Funding}

This study (ADC111891, NCT00791518) was funded by GlaxoSmithKline, Research Triangle Park, NC. The authors did not receive any money for writing the manuscript.

\section{Conflict of interest declarations}

Mark Dransfield has received COPD-related research funding from the NHLBI as well as Aeris, Altana/Nycomed/Forest, AstraZeneca, Boehringer Ingelheim, GSK, Novartis, Pfizer, and Roche. He has served on an advisory board for GSK and BI and has received speakers' honoraria from GSK and BI for COPD-related talks.

William Bailey has received research contracts from drug companies as sponsors of investigational drug research projects as well as speakers and advisory board honoraria. He has also received grants from the NIH which occasionally uses therapy/drugs from pharmaceutical companies. The pharmaceutical companies are: GlaxoSmithKline, AstraZeneca, Boehringer Ingelheim, Schering-Plough, Merck, Inspire, Pfizer, Aventis, Nycomed and Novartis.

Glenn Crater, Amanda Emmett, and Dianne O'Dell are GSK employees and own stock in the company.

Barbara Yawn has received research grants from GSK, Novartis and BI/Pfizer in the area of COPD screening and has served on the advisory committee for COPD related studies of GSK and BI-Pfizer.

\section{References}

1. Mannino DM, Homa DM, Akinbami U, Ford ES, Redd SC. Chronic obstructive pulmonary disease surveillance--United States, 1971-2000. MMWR Surveill Summ 2002;51(6):1-16.

2. Viegi G, Pistelli F, Sherrill DL, Maio S, Baldacci S, Carrozzi L. Definition, epidemiology and natural history of COPD. Eur Respir J 2007;30(5):993-1013. http://dx.doi.org/10.1183/09031936.00082507

3. Yawn B, Mannino D, Littlejohn T, et al. Prevalence of COPD among symptomatic patients in a primary care setting. Curr Med Res Opin 2009;25(11):2671-7.

4. National Heart, Lung and Blood Institute Chartbook, US Department of Health and Human Services, National Institute of Heath; 2004.

5. American LA. Trends in chronic bronchitis and emphysema: morbidity and mortality [Internet]. [cited 2010 Mar 29];Available from: http://www.lungusa.org

6. Price $D$, Crockett $A$, Arne $M$, et al. Spirometry in primary care case-identification, diagnosis and management of COPD. Prim Care Resp J 2009;18(3):216-23. http://dx.doi.org/10.4104/pcrj.2009.00055

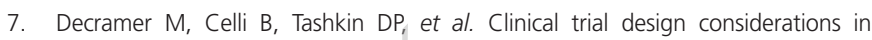
assessing long-term functional impacts of tiotropium in COPD: the UPLIFT trial. COPD 2004;1(2):303-12.

8. Sin DD, Anthonisen NR, Soriano JB, Agusti AG. Mortality in COPD: Role of comorbidities. Eur Respir J 2006;28(6):1245-57. http://dx.doi.org/ 10.1183/09031936.00133805

9. Yawn BP, Kaplan A. Co-morbidities in people with COPD: a result of multiple diseases, or multiple manifestations of smoking and reactive inflammation? Prim Care Resp J 2008;17(4):199-205. http://dx.doi.org/10.3132/pcrj.2008.00021

10. Yawn BP, Wollan PC. Knowledge and attitudes of family physicians coming to COPD continuing medical education. Int J Chron Obstruct Pulmon Dis 2008;3(2):311-17.

11. Rabe KF, Hurd S, Anzueto A, et al. Global strategy for the diagnosis, management, and prevention of chronic obstructive pulmonary disease: GOLD executive summary. Am J Respir Crit Care Med 2007;176(6):532-5. http://dx.doi.org/ 10.1164/rccm.200703-456SO

12. Bestall JC, Paul EA, Garrod R, Garnham R, Jones PW, Wedzicha JA. Usefulness of the Medical Research Council (MRC) dyspnoea scale as a measure of disability in patients with chronic obstructive pulmonary disease. Thorax 1999;54(7):581e6.

13. Schumemann JH, Puhan M, Goldstein R, Jaeschke R, Guyatt GH. Measurement properties and interpretability of the Chronic Respiratory Questionnaire (CRQ). J COPD 2005;2:81-9. http://dx.doi.org/10.1081/COPD-200050651

14. Mahler DA, Weinberg DH, Wells CK, Feinstein AR. The measurement of dyspnea. Contents, interobserver agreement, and physiologic correlates of two new clinical indexes. Chest 1984;85(6):751-8. http://dx.doi.org/10.1378/chest.85.6.751

15. Garcia-Rio F, Lores $V$, Mediano $O$, et al. Daily physical activity in patients with chronic obstructive pulmonary disease is mainly associated with dynamic hyperinflation. Am J Respir Crit Care Med 2009;180(6):506-12. http://dx.doi.org/10.1164/rccm.200812-18730C

16. Cazzola M, MacNee W, Martinez FJ, et al. Outcomes for COPD pharmacological trials: from lung function to biomarkers. Eur Respir J 2008;31(2):416-69. http://dx.doi.org/10.1183/09031936.00099306

17. Miravitlles M, Mayordomo C, Artés M, Sánchez-Agudo L, Nicolau F, Segú JL. Treatment of chronic obstructive pulmonary disease and its exacerbations in general practice. EOLO Group. Estudio Observacional de la Limitación Obstructiva al Flujo aEreo. Respir Med 1999;93(3):173-9. http://dx.doi.org/10.1016/S09546111(99)90004-5

18. Donaldson GC, Seemungal TAR, Bhowmik A, Wedzicha JA. Relationship between exacerbation frequency and lung function decline in chronic obstructive pulmonary disease. Thorax 2002;57(10):847-52. http://dx.doi.org/10.1136/thorax.57.10.847

19. Dewan NA, Rafique S, Kanwar B, et al. Acute exacerbation of COPD: factors associated with poor treatment outcome. Chest 2000;117(3):662-71. http://dx.doi.org/10.1378/chest.117.3.662

20. O'Reilly JF, Williams AE, Holt K, Rice L. Defining COPD exacerbations: impact on 
estimation of incidence and burden in primary care. Prim Care Resp J 2006;15(6):346-53. http://dx.doi.org/10.1016/j.pcrj.2006.08.009

21. Langsetmo L, Platt RW, Ernst P, Bourbeau J. Underreporting exacerbation of chronic obstructive pulmonary disease in a longitudinal cohort. Am J Respir Crit Care Med 2008;177(4):396-401. http://dx.doi.org/10.1164/rccm.200708-12900C

22. Celli BR, MacNee W; ATS/ERS Task Force. Standards for the diagnosis and treatment of patients with COPD: a summary of the ATS/ERS position paper. Eur Respir $J$ 2004;23(6):932-46. http://dx.doi.org/10.1183/09031936.04.00014304

23. Celli BR, Cote CG, Marin JM, et al. The body-mass index, airflow obstruction, dyspnea, and exercise capacity index in chronic obstructive pulmonary disease. $N$ Engl J Med 2004;350(10):1005-12. http://dx.doi.org/10.1056/NEJMoa021322

24. Jones PW, Harding G, Berry P, Wiklund I, Chen WH, Kline Leidy N. Development and first validation of the COPD Assessment Test. Eur Respir J 2009;34(3):648-54. http://dx.doi.org/10.1183/09031936.00102509

25. Han MK, Bartholmai B, Liu LX, Murray S, Curtis JL, Sciurba FC. Clinical significance of radiologic characterizations in COPD. COPD 2009;6(6):459-67.

26. National Clinical Guideline Centre. (2010) Chronic obstructive pulmonary disease: management of chronic obstructive pulmonary disease in adults in primary and secondary care London: National Clinical Guideline Centre. www.nice.org.uk/CG101

27. O'Donnell DE, Aaron S, Bourbeau J, et al. Canadian Thoracic Society recommendations for management of chronic obstructive pulmonary disease 2007 update. Can Respir J 2007;14 Suppl B:5B-32B.

28. Buffels J, Degryse J, Liistro G. Diagnostic certainty, co-morbidity and medication in a primary care population with presumed airway obstruction: the DIDASCO2 study. Prim Care Resp J 2009;18(1):34-40.

29. Knuiman MW, James AL, Divitini ML, Ryan G, Bartholomew HC, Musk AW. Lung function, respiratory symptoms, and mortality: results from the Busselton Health Study. Ann Epidemiol 1999;9(5):297-306. http://dx.doi.org/10.1016/S10472797(98)00066-0

30. Eisner MD, Blanc PD, Yelin EH, Katz PP, Sanchez G, Iribarren C, Omachi TA. Influence of anxiety on health outcomes in COPD. Thorax 2010;65(3):229-34. http://dx.doi.org/10.1136/thx.2009.126201

31. Nelson HS, Weiss ST, Bleecker ER, Yancey SW, Dorinsky PM; SMART Study Group. The Salmeterol Multicenter Asthma Research Trial: a comparison of usual pharmacotherapy for asthma or usual pharmacotherapy plus salmeterol. Chest 2006;129(1):15-26. http://dx.doi.org/10.1378/chest.129.1.15

32. Calverley PM, Burge PS, Spencer S, Anderson JA, Jones PW. Bronchodilator reversibility testing in chronic obstructive pulmonary disease. Thorax 2003;58(8):647-8. http://dx.doi.org/10.1136/thorax.58.8.659

33. Hanania NA, Darken $P$, Horstman $D$, et al. The efficacy and safety of fluticasone propionate (250 microg)/salmeterol (50 microg) combined in the Diskus inhaler for the treatment of COPD. Chest 2003;124(3):834-43. http://dx.doi.org/ 10.1378/chest.124.3.834

34. Tashkin DP, Celli B, Senn S, et al. A 4-year trial of tiotropium in chronic obstructive pulmonary disease. N Engl J Med 2008;359(15):1543-54. http://dx.doi.org/ 10.1056/NEJMOa0805800

\section{Available online at http://www.thepcrj.org}

